\title{
Effect of casopitant, a novel NK-1 antagonist, on the pharmacokinetics of dolasetron and granisetron
}

\author{
Laurel M. Adams • Brendan Johnson • Ke Zhang • \\ Lin Yue • Lyndon C. Kirby • Peter Lebowitz • \\ Randall Stoltz
}

Received: 31 July 2008 / Accepted: 22 December 2008 / Published online: 10 February 2009

(C) The Author(s) 2009. This article is published with open access at Springerlink.com

\begin{abstract}
Objective The objective of this study was to characterize the impact of casopitant, a novel neurokinin-1 receptor antagonist under investigation for the prevention of postoperative and chemotherapy-induced nausea and vomiting, on the pharmacokinetics of the commonly prescribed 5-hydroxytryptamine receptor 3 receptor antagonists, dolasetron or granisetron.

Materials and methods In a phase I, open-label, two-part, two-period, single-sequence study, two cohorts of healthy subjects received either oral dolasetron (100 $\mathrm{mg}$ once daily for 3 days) or oral granisetron ( $2 \mathrm{mg}$ once daily for 3 days) alone (period 1) and combined with oral casopitant, $150 \mathrm{mg}$
\end{abstract}

Presented as an invited lecture at the Supportive Care in Cancer MASCC/ISOO 2008 International Symposium in Houston, TX, USA on June 26-28, 2008

This work was sponsored by GlaxoSmithKline. R Stoltz received funding from GlaxoSmithKline to conduct this study. All other authors were employees of GlaxoSmithKline.

L. M. Adams $(\bowtie) \cdot$ B. Johnson $\cdot$ K. Zhang $\cdot$ L. C. Kirby

GlaxoSmithKline,

Five Moore Drive,

Research Triangle Park, NC 27709, USA

e-mail: laurel.m.adams@gsk.com

L. Yue $\cdot$ P. Lebowitz

GlaxoSmithKline,

Collegeville, PA, USA

R. Stoltz

Covance,

Evansville, IN, USA

Present address:

K. Zhang

Pfizer,

San Diego, CA, USA day 1, $50 \mathrm{mg}$ days 2 and 3 (period 2). Pharmacokinetics of hydrodolasetron and granisetron were assessed on days 1 and 3 of each period. Log-transformed area under the curve (AUC) and Cmax were statistically analyzed by performing an analysis of variance. Eighteen subjects were enrolled in the dolasetron cohort; nine subjects were CYP2D6 extensive metabolizers (EMs) and nine subjects were CYP2D6 poor metabolizers. Nineteen subjects were enrolled in the granisetron cohort.

Results The largest changes in hydrodolasetron exposure after coadministration with casopitant were seen in CYP2D6 EMs, with a $24 \%$ increase in hydrodolasetron AUC on day 1 and $30 \%$ increase in Cmax on days 1 and 3 . All other changes in hydrodolasetron exposure were $<20 \%$, and granisetron exposure was not altered to any relevant extent $(<11 \%)$.

Conclusion None of the changes observed are considered clinically meaningful, and coadministration of casopitant with dolasetron or granisetron was well tolerated.

Keywords Casopitant · Dolasetron · Granisetron . $\mathrm{CINV} \cdot 5-\mathrm{HT}_{3}$

\section{Introduction}

Emesis is an autonomic reflex controlled by multiple neurotransmitter systems; two of the most important are the serotonin/5-hydroxytryptamine receptor $3\left(5-\mathrm{HT}_{3}\right)$ and substance P/neurokinin-1 receptor (NK-1) systems [13]. Blocking both the 5- $\mathrm{HT}_{3}$ and NK-1 neurotransmitter receptors has been demonstrated to prevent chemotherapyinduced nausea and vomiting in patients receiving chemotherapy $[6,11,12,20,29]$. According to guidelines established by the Multinational Association for Supportive 
Care in Cancer [23], patients who will receive a moderately emetogenic chemotherapy (MEC) regimen should receive a $5-\mathrm{HT}_{3}$ receptor antagonist and dexamethasone for the prevention of chemotherapy-induced nausea and vomiting (CINV), while patients who will receive a MEC regimen that includes anthracycline and cyclophosphamide or a highly emetogenic chemotherapy (HEC) regimen should receive a $5-\mathrm{HT}_{3}$ receptor antagonist, a corticosteroid, and an NK-1 receptor antagonist [23, 25].

NK-1 receptor antagonists have also shown efficacy in the treatment and prevention of postoperative nausea and vomiting (PONV), both alone and in combination with a 5$\mathrm{HT}_{3}$ receptor antagonist $[7,10,28]$. Without prophylactic antiemetics, approximately $20-30 \%$ of surgical patients experience PONV $[18,30]$, and, in the highest-risk patients, PONV may occur in up to $70-80 \%$ of cases $[1,9]$.

Casopitant, a novel NK-1 receptor antagonist, is under investigation as part of a three-drug antiemetic regimen including a $5-\mathrm{HT}_{3}$ receptor antagonist and corticosteroid for patients receiving MEC or HEC. In clinical studies, casopitant is a weak to moderate inhibitor of the drugmetabolizing enzyme CYP3A (depending on dose and duration of dosing) but does not appear to have any significant impact on CYP2D6 after 50 or $100 \mathrm{mg}$ single oral doses of casopitant as assessed by the CYP2D6 probe, debrisoquine (unpublished data, GlaxoSmithKline 2006).

In vivo, the $5-\mathrm{HT}_{3}$ receptor antagonist dolasetron is rapidly reduced (half-life of less than $15 \mathrm{~min}$ [17]) by ubiquitous carbonyl reductases to its metabolically active form, hydrodolasetron, which is largely responsible for the pharmacologic activity ([3, 8] and references therein). Hydrodolasetron is further metabolized by CYP2D6 with minor involvement of CYP3A4 [26]. Plasma exposures of hydrodolasetron are increased approximately threefold in CYP2D6 poor metabolizers (PMs) as compared to extensive metabolizers (EMs) [19]. For CYP2D6 PMs, CYP3A4 is likely to play a larger role in the clearance of hydrodolasetron, and these subjects may be more sensitive to coadministration of inhibitors of CYP3A, such as casopitant. In vitro, granisetron is primarily metabolized by CYP1A1 and CYP3A4 $[4,24]$ and therefore plasma levels of granisetron also may be increased when coadministered with casopitant.

The aim of this study was to assess the impact of a 3-day regimen of casopitant on the pharmacokinetics of repeat doses of oral dolasetron (as assessed by hydrodolasetron exposure) or granisetron. The pharmacokinetics of casopitant were not assessed since neither (hydro)dolasetron nor granisetron are significant inhibitors of cytochrome P450 (CYP) enzymes and are therefore unlikely to impact the clinical pharmacokinetics of casopitant to any relevant extent $[2,4]$. In addition, acute, usually reversible, cardiac effects including QTc prolongation have been observed following dolasetron administration [2]. Arrhythmias such as bradycardia have been observed with other $5-\mathrm{HT}_{3}$ receptor antagonists, although to a lesser extent. Therefore, a PK interaction that may lead to increased hydrodolasetron or granisetron plasma concentrations has the potential to increase the risk of electrocardiogram (ECG) abnormalities. Therefore, this study also evaluated the potential for ECG changes following administration of dolasetron or granisetron with oral casopitant.

\section{Subjects and methods}

\section{Subject population}

Male and female subjects of 18 to 64 years of age, body mass index of $\geq 19$ to $\leq 37 \mathrm{~kg} / \mathrm{m}^{2}$, and adequate organ function were eligible to enter the study. All females of childbearing potential were required to use birth control from 14 days before the first dose of study medication, throughout the study, and for 14 days after the last dose of study medication. Exclusion criteria were designed to ensure that subjects were in good health and not receiving concomitant medications that could interfere with the pharmacokinetics of study medications.

For the dolasetron cohort, subjects were eligible only if they were determined to be either CYP2D6 PMs $(* 3, * 4$, $* 5$, *6, or *7 homozygotes) or CYP2D6 EMs (absence or heterozygotes for $* 3, * 4, * 5, * 6$, or $* 7$ alleles and devoid of CYP2D6 gene duplication) by genotypic analysis ([21] Gentris, Morrisville NC, USA). Approximately an equal number of CYP2D6 EMs and PMs were to be enrolled in the dolasetron cohort of the study.

The study protocol and informed consent documents were reviewed and approved by an institutional review board and subjects provided written consent prior to participation in the trial. All investigators were required to abide by Good Clinical Practices, International Conference on Harmonization guidelines, Declaration of Helsinki principles, and local laws and regulations.

\section{Study design}

This was a phase I, open-label, two-part, two-period, single-sequence study. Two cohorts of subjects received either oral dolasetron (100 mg once daily for 3 days) or oral granisetron (2 $\mathrm{mg}$ once daily for 3 days) alone (period 1) and then combined (period 2) with oral casopitant (150 mg day $1,50 \mathrm{mg}$ days 2 and 3). Each period was separated by a window of 5 to 14 days. During period 2, casopitant was coadministered at the same time with either dolasetron or granisetron. All doses of study medication were taken after at least a $2 \mathrm{~h}$ fasting period. Plasma pharmacokinetics of 
hydrodolasetron and granisetron were assessed on days 1 and 3 of each period with blood samples collected predose and $0.5,1,1.5,2,3,4,6,8,12,16$, and $24 \mathrm{~h}$ postdose. Safety was assessed through adverse-event reporting and evaluation of clinical laboratory parameters and vital signs. In both periods, 12-lead electrocardiograms were performed on days 1 to 3 prior to administration of dolasetron or on day 1 prior to administration of granisetron.

\section{Pharmacokinetics}

Human ethylenediaminetetraacetic acid plasma samples (50 $\mu \mathrm{L}$ aliquot) were analyzed for hydrodolasetron or granisetron using validated analytical methods based on protein precipitation, followed by high-performance liquid chromatography/mass spectrometry (MS)/MS analysis. For hydrodolasetron, the lower and upper limits of quantification were 1 and $1,000 \mathrm{ng} / \mathrm{mL}$, respectively. For granisetron, the lower and upper limits of quantification were 0.1 and $100 \mathrm{ng} / \mathrm{mL}$, respectively. Quality control (QC) samples, prepared at three different analyte concentrations and stored with study samples, were analyzed with each batch of samples against separately prepared calibration standards. For the analysis to be acceptable, no more than one third of the QC results were to deviate from the nominal concentration by more than $15 \%$, and at least $50 \%$ of the results from each QC concentration should be within $15 \%$ of nominal. The applicable analytical runs met all predefined run acceptance criteria.

Pharmacokinetic parameters area under the curve (AUC)(0- $\tau)$ and Cmax were determined on both days 1 and 3 in periods 1 and 2 using standard non-compartmental methods (WinNonlin, version 4.1, Pharsight Corp, Mountain View, CA, USA).

\section{Statistics}

An estimation approach was taken to determine the magnitude of the interaction between hydrodolasetron or granisetron and casopitant. AUC and Cmax were statistically analyzed by performing an analysis of variance (ANOVA) on $\log (\mathrm{e})$-transformed data in order to compute an estimate of the geometric least-square mean ratios and $90 \%$ confidence intervals (CI) for $\mathrm{AUC}(0-\tau)$ and Cmax comparing the test treatment in period $2\left(5 \mathrm{HT}_{3}+\right.$ casopitant) to the reference treatment in period 1 ( $5 \mathrm{HT}_{3}$ alone). No clinically meaningful interaction effect was assumed if the $90 \%$ CI for the mean ratio was completely within the interval of 0.8 to 1.25 .

For the dolasetron cohort, the ANOVA used a mixedeffects model with subject as a random effect and treatment, day, and population (CYP2D6 EM or PM) as well as all two- and three-way interactions of treatment, day, and population as fixed effects. For the granisetron cohort, the
ANOVA used a mixed-effects model with subject as a random effect and treatment, day, and treatment-by-day interaction as fixed effects.

A sufficient number of subjects were enrolled to ensure that at least 12 evaluable subjects completed each part of the study. In the dolasetron arm, a minimum of six CYP2D6 PMs and six EMs were to complete the study. With the assumption that the within-subject coefficient of variation $(\mathrm{CV})$ is $41 \%$, the lower and upper bounds of the $90 \%$ CI for the ratio of the geometric means for pharmacokinetic parameters were calculated to be within $19 \%$ of the point estimates. This calculation was based on a symmetric two-tailed procedure on the $\log (\mathrm{e})$ scale and a type I error rate of $5 \%$ in each tail. In the granisetron arm, with the assumption of the within-subject CV of $23 \%$, a sample size of 12 evaluable subjects, and similar analysis procedure as described above, the lower and upper bounds of the $90 \%$ CI were calculated to be within $10 \%$ of the point estimates.

\section{Results}

A total of 18 healthy adult subjects were enrolled in the dolasetron cohort; nine subjects were CYP2D6 EMs and nine subjects were CYP2D6 PMs. A total of 19 healthy adult subjects were enrolled in the granisetron cohort. Demographic characteristics are summarized in Table 1.

\section{Dolasetron}

Coadministration of casopitant with dolasetron resulted in slight increases in mean hydrodolasetron AUC and Cmax on days 1 and 3, with no mean increase in exposure of more than 25\% (Table 2). All 90\% CIs for hydrodolasetron AUC ratios were within the range of 0.8 to 1.25 ; however, the upper bound was exceeded for ratios of hydrodolasetron Cmax. In the CYP2D6 EM population, there were $24 \%$ and $10 \%$ mean increases in hydrodolasetron AUC on days 1 and 3, respectively, and 30\% mean increases in Cmax on both days 1 and 3. CYP2D6 PMs exhibited approximately twice the exposure to hydrodolasetron as CYP2D6 EMs when dolasetron was administered alone (Fig. 1). However, after coadministration with casopitant, CYP2D6 PMs exhibited smaller changes in hydrodolasetron AUC and Cmax compared to CYP2D6 EMs. For CYP2D6 PMs, only the day $3 \mathrm{Cmax}$ parameter ratio exceeded the predefined $90 \%$ CI range of 0.8 to 1.25 , with a mean increase of $14 \%$.

\section{Granisetron}

Coadministration of casopitant with granisetron resulted in mean increases in granisetron AUC and Cmax of $11 \%$ or 
Table 1 Demographic characteristics of enrolled subjects

\begin{tabular}{lll}
\hline Characteristic & Dolasetron cohort, $n=18$ & Granisetron cohort, $n=19$ \\
\hline Age in years, mean (range) & $30.3(21-41)$ & $41.3(20-64)$ \\
Sex, $n(\%)$ & $1(6 \%)$ & $17(89 \%)$ \\
Female & $17(94 \%)$ & $2(11 \%)$ \\
Male & $176.6(168-190)$ & $163.6(156-180)$ \\
Height, cm (mean and range) & $88.41(59.1-125)$ & $70.2(54.1-98.2)$ \\
Weight, $\mathrm{kg}$ (mean and range) & $28.25(18.84-36.55)$ & $26.14(21.03-35.64)$ \\
BMI, $\mathrm{kg} / \mathrm{m}^{2}$ (mean and range) & & $2(11 \%)$ \\
Race, $n(\%)$ & $3(17 \%)$ & $16(84 \%)$ \\
African American/African heritage & $15(83 \%)$ & $1(5 \%)$ \\
White/Caucasian/European heritage & 0 & NA \\
Mixed race & & NA \\
Genotype, $n$ (\%) & $9(50 \%)$ &
\end{tabular}

$N A$ not applicable

less (Table 2). The day $190 \%$ CIs for AUC and Cmax were just outside the 0.8 to 1.25 interval, but the $90 \%$ CIs were within the interval on day 3 . Results from individual subjects are illustrated in Fig. 2.

\section{Safety}

Coadministration of casopitant and dolasetron or granisetron was well tolerated. Adverse-event frequencies are summarized in Table 3. The most common adverse event was headache which occurred at a lower frequency in casopitant-containing regimens. When casopitant was coadministered with dolasetron, the adverse-event profile was similar to dolasetron administered alone. When casopitant was coadministered with granisetron, the incidence of somnolence increased and the incidence of constipation decreased compared to granisetron administered alone. All adverse events were mild or moderate in intensity, and all events resolved. There were no serious adverse events and no deaths. Changes in clinical laboratory values, vital signs, and ECGs were not clinically meaningful.
Fig. 1 Day 1 and day 3 hydrodolasetron $\operatorname{AUC}(0-\tau)$ and $\mathrm{Cmax}$ when a 3-day regimen of $100 \mathrm{mg}$ oral dolasetron is given alone and in combination with a 3-day oral regimen of casopitant in CYP2D6 EMs (circles) and CYP2D6 PMs (triangles)
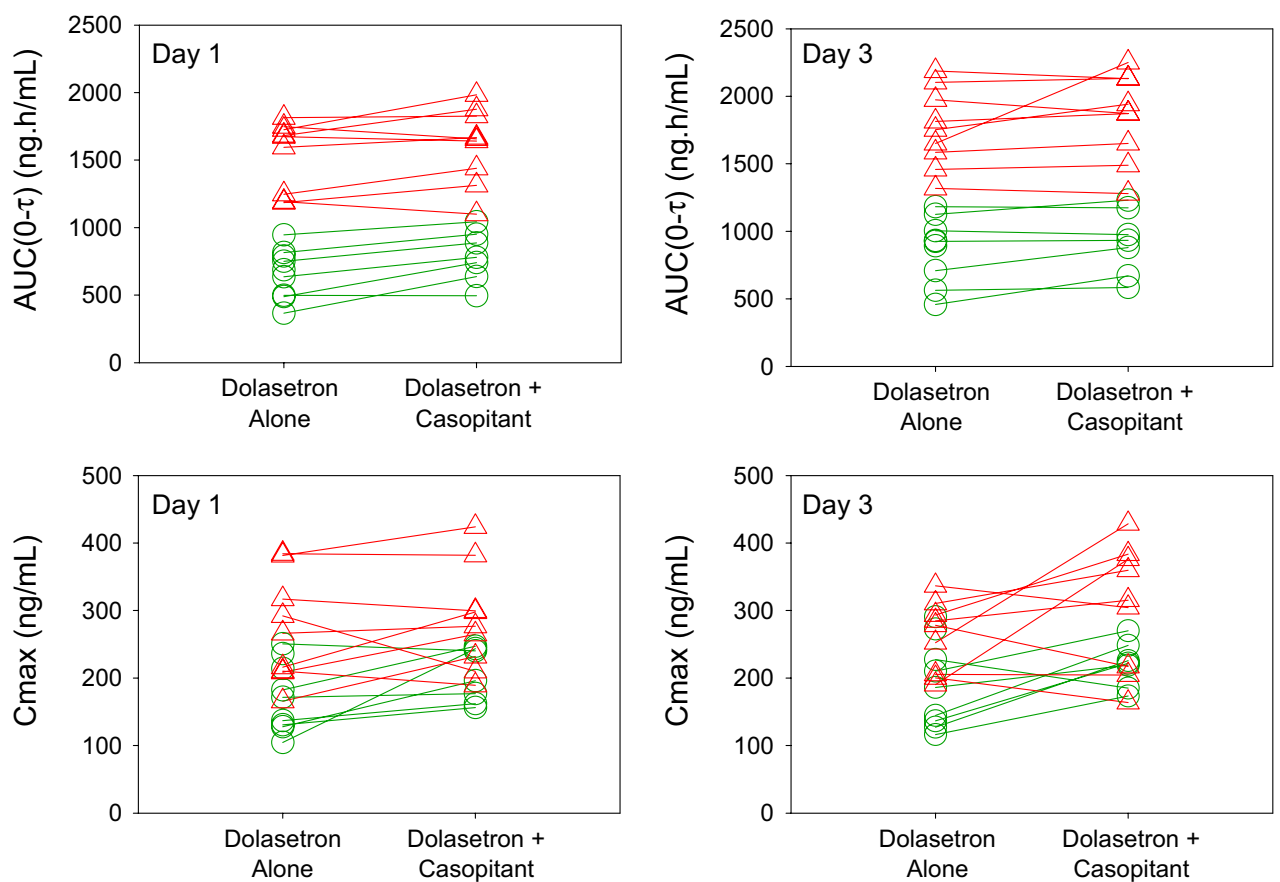
Table 2 Change in hydrodolasetron and granisetron AUC and Cmax when coadministered with casopitant (ratio of dolasetron or granisetron plus casopitant to dolasetron or granisetron alone)

\begin{tabular}{llcrr}
\hline Analyte & Population & Day & AUC ratio (90\% CI) & Cmax ratio (90\% CI) \\
\hline Hydrodolasetron & All & 1 & $1.14(1.08,1.20)$ & $1.18(1.06,1.31)$ \\
& CYP2D6 EMs & 3 & $1.07(1.03,1.13)$ & $1.22(1.10,1.36)$ \\
& & 1 & $1.24(1.15,1.34)$ & $1.30(1.11,1.53)$ \\
CYP2D6 PMs & 3 & $1.10(1.02,1.19)$ & $1.31(1.11,1.53)$ \\
Granisetron & & 1 & $1.05(0.97,1.12)$ & $1.06(0.92,1.23)$ \\
& All & 3 & $1.05(0.98,1.12)$ & $1.14(0.99,1.32)$ \\
& & 1 & $1.08(0.93,1.26)$ & $1.11(0.95,1.29)$ \\
& & 3 & $1.00(0.86,1.17)$ & $1.04(0.89,1.22)$ \\
\hline
\end{tabular}

\section{Discussion}

This study examined the potential for pharmacokinetic interactions between oral casopitant and repeat-dose oral dolasetron or granisetron using the highest oral dose of casopitant currently under investigation for the prevention of CINV, i.e., $150 \mathrm{mg}$ on day 1 , followed by $50 \mathrm{mg}$ on days 2 and 3. An intravenous formulation of $90 \mathrm{mg}$ casopitant is also under investigation; however, as oral administration results in higher gut and liver concentrations of study drug and these sites are known to have higher concentrations of CYP enzymes and thus higher potential CYP inhibition [16], less significant interactions would be expected after intravenous administration of casopitant.

Clinical studies using coadministration of oral midazolam have demonstrated that casopitant results in weak to moderate inhibition of CYP3A in the oral dose range of 50 to $150 \mathrm{mg}$ but no inhibition of CYP2D6 using debrisoquine as a probe with single oral doses up to $100 \mathrm{mg}$ and there is no in vitro evidence that casopitant is a significant inhibitor of CYP1A enzymes (unpublished data, GlaxoSmithKline).

The major circulating active metabolite of dolasetron, hydrodolasetron, is metabolized by CYP2D6 and, to a lesser extent, by CYP3A4. The current study showed that coadministration of dolasetron with a 3-day regimen of casopitant resulted in no clinically relevant change in the exposure of hydrodolasetron. The largest observed changes were a $14 \%$ increase in hydrodolasetron AUC on day 1 and $18 \%$ and $22 \%$ increases in hydrodolasetron Cmax on days 1 and 3 , respectively. These changes are not considered clinically relevant, were not associated with any increase in adverse events, and were within the same range of withinsubject variability for dolasetron exposure $(41 \%$ as described in "Statistics").
Fig. 2 Day 1 and day 3 granisetron $\operatorname{AUC}(0-\tau)$ and $\operatorname{Cmax}$ when a 3-day regimen of $2 \mathrm{mg}$ oral granisetron is given alone and in combination with a 3-day oral regimen of casopitant
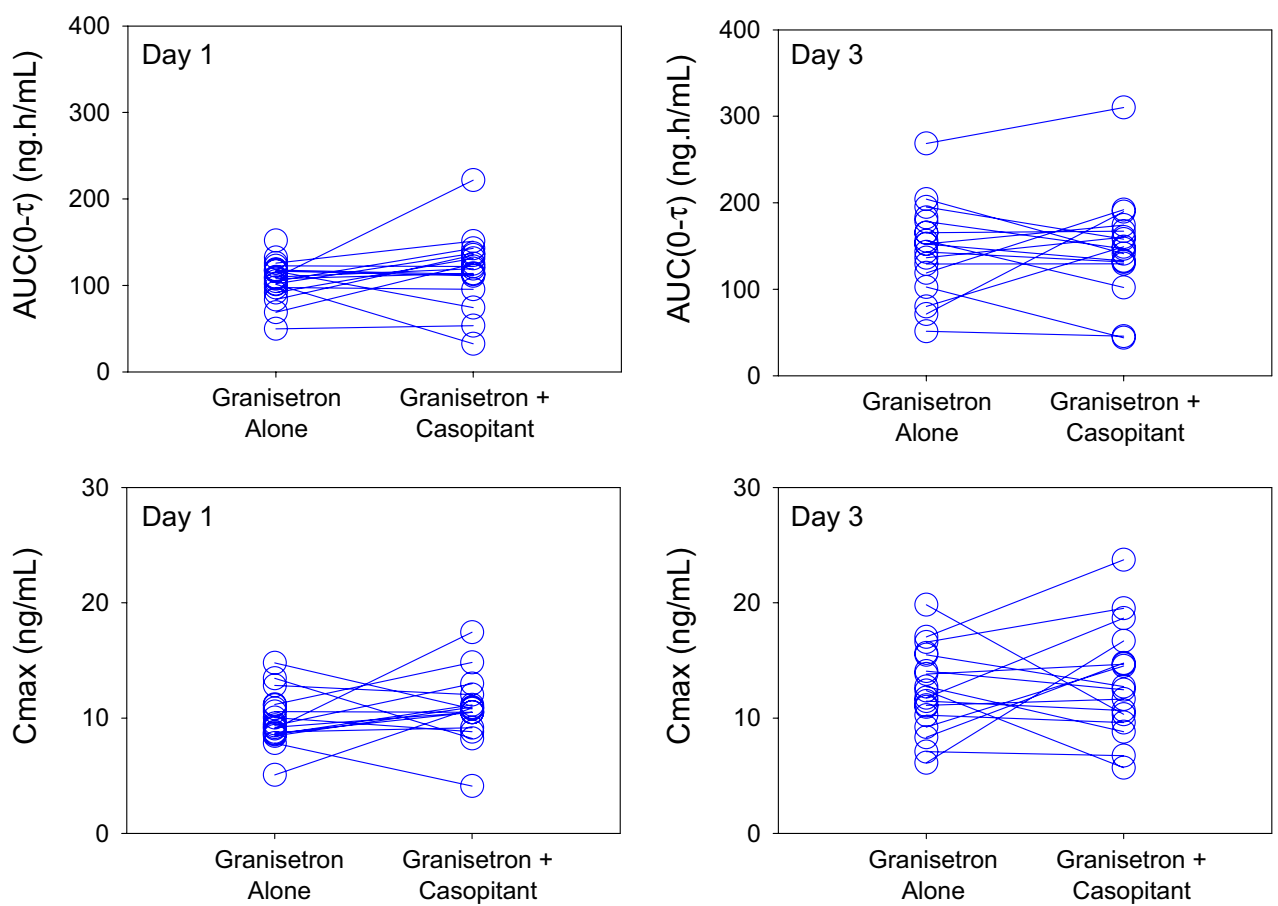
Table 3 Adverse events reported in two or more subjects

\begin{tabular}{lllll}
\hline & $\begin{array}{l}\text { Dolasetron, } \\
N=18, n(\%)\end{array}$ & $\begin{array}{l}\text { Dolasetron + casopitant, } \\
N=18, n(\%)\end{array}$ & $\begin{array}{l}\text { Granisetron, } \\
N=19, n(\%)\end{array}$ & $\begin{array}{l}\text { Granisetron + casopitant, } \\
N=18, n(\%)\end{array}$ \\
\hline Subjects with any adverse event & $5(28 \%)$ & $4(22 \%)$ & $11(58 \%)$ & $7(39 \%)$ \\
Headache & $4(22 \%)$ & $1(6 \%)$ & $5(26 \%)$ & $2(11 \%)$ \\
Somnolence & $1(6 \%)$ & $3(17 \%)$ & 0 & $5(28 \%)$ \\
Dizziness & $1(6 \%)$ & $1(6 \%)$ & $1(5 \%)$ & $1(6 \%)$ \\
Constipation & 0 & 0 & $6(32 \%)$ & $1(6 \%)$ \\
\hline
\end{tabular}

CYP2D6 is responsible for a large proportion of hydrodolasetron clearance and is polymorphically expressed. CYP2D6 PMs had only approximately twofold higher hydrodolasetron exposure than CYP2D6 EMs in this study (Fig. 1). There is a theoretical potential for increased pharmacokinetic interaction between casopitant and hydrodolasetron in CYP2D6 PMs as CYP3A4 is likely to comprise a larger proportion of hydrodolasetron clearance in these subjects. The majority of the Caucasian population (70\%) would be classified as CYP2D6 EMs, requiring just one copy of a functional CYP2D6 allele $(* 1$ or *2); however, $51 \%$ of the African American population are EMs and $35 \%$ would be classified as reduced function or intermediate metabolizers. The frequency of PM status (non-functional alleles) is $5-10 \%$ in Caucasian populations and $15 \%$ in African Americans [5].

The statistical analysis of hydrodolasetron exposure in CYP2D6 EMs and PMs (Table 2) shows that CYP2D6 PMs did not exhibit significant increases in hydrodolasetron exposure when dolasetron was coadministered with casopitant. Likewise in CYP2D6 EMs, although hydrodolasetron exposure was increased 10\% (AUC) to 31\% (Cmax), these increases were not considered clinically relevant since the slightly higher hydrodolasetron exposures in CYP2D6 EMs in the presence of casopitant were still substantially lower than those observed in CYP2D6 PMs with dolasetron alone. While the interaction observed in EMs and PMs was not as anticipated, the changes in AUC in both groups were small $(<25 \%)$ and are likely to reflect the small subject numbers in each population, subject to subject variability and the ability of hydrodolasetron to be metabolized by multiple CYP enzymes.

When granisetron, which is primarily metabolized by CYP1A1 and CYP3A4, was coadministered with casopitant, changes in exposure were minor (mean increases in exposure of less than or equal to $11 \%$ ) and were not associated with any change in the safety or adverse-event profile of granisetron that would not be considered clinically important given that the within-subject variability for granisetron exposure is approximately 23\% (see "Statistics").
Coadministration of casopitant and dolasetron or granisetron was well tolerated. All adverse events were mild or moderate in intensity, and all events resolved. The ECG effects of hydrodolasetron are dose dependent and were reported to be observed at single doses greater than $200 \mathrm{mg}$ [19]. Since the recommended oral dose of dolasetron of $100 \mathrm{mg}$ was utilized in the present study, increase in plasma concentration of up to twofold or $100 \%$ (equal to a $200-\mathrm{mg}$ dose) can be considered clinically unimportant for the 100 $\mathrm{mg}$ dose. The maximum increase in Cmax seen in the present study was only 31\%. Moreover, no apparent differences in cardiac function (QTc, bradycardia) occurred when either dolasetron or granisetron was coadministered with casopitant. Similarly, no effect on cardiac function of casopitant coadministered with the serotonin antagonist ondansetron was recently reported [15]. Further, Li et al. [19] have reported that there is no effect of a similar NK-1 receptor antagonist, aprepitant, on the $\mathrm{PK}$ and cardiac safety profile of hydrodolasetron in CYP2D6 EMs or PMs. Consequently, these findings, coupled with no clinically important increase in hydrodolasetron or granisetron exposure in the presence of casopitant, suggest that casopitant is unlikely to increase the potential for either of these drugs to elicit life-threatening arrhythmias. Similar insignificant changes in ondansetron exposure and safety have been observed in another drug-drug interaction study with casopitant [14]. While the majority of subjects in the dolasetron cohort were male and the majority in the granisetron cohort were female, previous unpublished studies have shown that casopitant pharmacokinetics is similar in male and female subjects. Casopitant, therefore, would be expected to have a similar inhibitory potential on CYP3Ametabolizing enzymes and result in similar observations to those observed in the current study.

Given that palonosetron is also metabolized by the same mixed CYP enzymes as other $5-\mathrm{HT}_{3}$ receptor antagonists (CYP2D6, 3A4, 1A2) and is administered intravenously [22], no drug-drug interaction of clinical relevance between casopitant and palonosetron would be anticipated. Indeed, a study investigating the concomitant administration of another NK-1 receptor antagonist, aprepitant, and IV 
palonosetron concluded that no dosage adjustment of either agent was needed when administered together [27]. The current study demonstrates that casopitant coadministered with the $5-\mathrm{HT}_{3}$ receptor antagonists dolasetron or granisetron does not result in clinically relevant changes in the pharmacokinetics or safety of these agents and that these combinations may be used in antiemetic regimens for the prevention of PONV or CINV.

Acknowledgements The authors acknowledge the assistance of Sabrina Pagliarusco for the bioanalysis of plasma samples and WynneWords LLC in the preparation of this manuscript.

Open Access This article is distributed under the terms of the Creative Commons Attribution Noncommercial License which permits any noncommercial use, distribution, and reproduction in any medium, provided the original author(s) and source are credited.

\section{References}

1. Apfel CC, Laara E, Koivuranta M et al (1999) A simplified risk score for predicting postoperative nausea and vomiting. Anesthesiology 91:693-700. doi:10.1097/00000542-199909000-00022

2. Aventis (2006) Anzemet prescribing information. June

3. Bigaud M, Elands J, Kastner PR et al (1995) Pharmacology of the human metabolites of dolasetron, an antiemetic $5-\mathrm{HT}_{3}$ receptor antagonist. Drug Dev Res 34:289-296. doi:10.1002/ ddr.430340306

4. Bloomer JC, Baldwin SJ, Smith GJ et al (1994) Characterization of the cytochrome P450 enzymes involved in the in vitro metabolism of granisetron. Br J Clin Pharmacol 38:557-566

5. Bradford LD (2002) CYP2D6 allele frequency in European Caucasians, Asians, Africans, and their descendants. Pharmacogenomics 3:229-243. doi:10.1517/14622416.3.2.229

6. De Mulder PH, Seynaeve C, Vermorken JB et al (1990) Ondansetron compared with high-dose metoclopramide in prophylaxis of acute and delayed cisplatin-induced nausea and vomiting. A multicenter, randomized, double-blind, crossover study. Ann Intern Med 113:834-840

7. Diemunsch P, Schoeffler P, Bryssine B et al (1999) Antiemetic activity of the NK1 receptor antagonist GR205171 in the treatment of established postoperative nausea and vomiting after major gynaecological surgery. Br J Anaesthesia 82:274276.1

8. Dimmit DC, Cramer MB, Keung A et al (1999) Pharmacokinetics of dolasetron with coadministration of cimetidine or rifampin in healthy subjects. Cancer Chemother Pharmacol 43:126-132. doi: $10.1007 / \mathrm{s} 002800050872$

9. Gan TJ, Mayer T, Apfel CC et al (2003) Consensus guidelines for managing postoperative nausea and vomiting. Anesth Analg 97 (1):62-71. doi:10.1213/01.ANE.0000068580.00245.95

10. Gan TJ, Apfel CC, Kovac A (2007) A randomized, double-blind comparison of the $\mathrm{NK}_{1}$ antagonist, aprepitant. Ondansetron Prev Postoperative Nausea Vomiting Anesth Analg 104(5):1082-1089

11. Grunberg S (2008) Phase III results of a novel neurokinin-1 (NK-1) receptor antagonist, casopitant: single oral and 3-day oral dosing regimens for chemotherapy-induced nausea and vomiting (CINV) in patients (Pts) receiving moderately emetogenic chemotherapy (MEC). J Clin Oncol 26:9540. doi:10.1200/ JCO.2008.18.7559

12. Herrstedt J (2008) Phase III results for the novel neurokinin-1 (NK-1) receptor antagonist, casopitant: single oral dosing regimen for chemotherapy-induced nausea and vomiting (CINV) in patients (Pts) receiving highly emetogenic chemotherapy (HEC). J Clin Oncol 26:9549

13. Hesketh PJ (2004) Management of nausea and vomiting in cancer and cancer treatment. Jones \& Bartlett, Sudbury

14. Johnson B, Adams L, Lu E et al (2008) Minimal impact of casopitant, a novel NK-1 antagonist, on the pharmacokinetics of ondansetron and dexamethasone. J Support Care Cancer, companion paper. doi:10.1007/s00520-008-0571-5

15. Johnson B, Zhang K, Fang L et al (2008) Use of modeling and simulation in the QTC assessment of casopitant. J Clin Pharmacol 48:1114. doi:10.1177/0091270008321940. Abstract 67

16. Kato M (2008) Intestinal first pass metabolism of CYP3A4 substrates. Drug Metab Pharmacokinet 23(2):87-94. doi:10.2133/ dmpk.23.87

17. Keung ACF, Landriault H, LeFebvre M et al (1997) Pharmacokinetics and safety of single intravenous and oral doses of dolasetron mesylate in healthy women. Biopharm Drug Dispos 18(4):361-369 doi:10.1002/(SICI)1099-081X(199705)18:4<361:: AID-BDD25>3.0.CO;2-I

18. Kovac A (2000) Prevention and treatment of postoperative nausea and vomiting. Drugs 59(2):212-243. doi:10.2165/00003495200059020-00005

19. Li SX, Pequignot E, Panebianco D (2006) Lack of effect of aprepitant on hydrodolasetron pharmacokinetics in CYP2D6 extensive and poor metabolizers. J Clin Pharmacol 46:792-801. doi: $10.1177 / 0091270006288954$

20. Marty M, Pouillart P, Scholl S et al (1990) Comparison of the 5hydroxytryptamine3 (serotonin) antagonist ondansetron (GR $38032 \mathrm{~F}$ ) with high-dose metoclopramide in the control of cisplatin-induced emesis. N Engl J Med 322:816-821

21. McElroy S, Richmond J, Lira M et al (2000) CYP2D6 genotyping as an alternative to phenotyping for determination of metabolic status in a clinical setting. AAPS PharmSci 2(4):1-11. doi: $10.1208 / p s 020433$

22. MGI Pharma (2007) Aloxi prescribing information. September

23. Multinational Association of Supportive Care in Cancer (2008) Antiemetic subcommittee guidelines. http:/www.mascc.org

24. Nakamura H, Ariyoshi N, Okada K et al (2005) CYP1A1 is a major enzyme responsible for the metabolism of granisetron in human liver microsomes. Curr Drug Metab 6:469-480. doi: $10.2174 / 138920005774330666$

25. Roila F, Hesketh PJ, Herrstedt J (2006) Prevention of chemotherapyand radiotherapy-induced emesis: results of the 2004 Perugia international antiemetic consensus conference. Ann Oncol 17:20 28. doi:10.1093/annonc/mdj936

26. Sanwald P, David M, Dow J (1996) Characterization of the cytochrome P450 enzymes involved in the in vitro metabolism of dolasetron. Drug Metab Dispos 24(5):602-609

27. Shah AK, Hunt TL, Gallagher SC et al (2005) Pharmacokinetics of palonosetron in combination with aprepitant in healthy volunteers. Curr Med Res Opin 21:595-601. doi:10.1185/030079905X40481

28. Singla N, Chung F, Singla S, Grenier A, Kutsogiannis D, Kett A, Pergolizzi J, Russo M (2006) Efficacy of oral casopitant mesylate, a novel neurokinin-1 receptor antagonist, with intravenous ondansetron $\mathrm{HCl}$ in the prevention of postoperative nausea and vomiting (PONV) in high-risk patients. Eur J Anaesthesiol 23(S37):A614

29. Warr DG, Hesketh PJ, Gralla RJ et al (2005) Efficacy and tolerability of aprepitant for the prevention of chemotherapyinduced nausea and vomiting in patients with breast cancer after moderately emetogenic chemotherapy. J Clin Oncol 23:28222830. doi:10.1200/JCO.2005.09.050

30. Watcha MF, Jones MB, Lagueruela RG (1992) Comparison of ketorolac and morphine as adjuvants during pediatric surgery. Anesthesiology 76(3):368-372. doi:10.1097/00000542199203000-00008 